\title{
Teaching Clinical Pharmacology to Undergraduate Nursing Students: Barriers and Strategies
}

\author{
Victoria Foster, Elicia Collins, Han Dong, Grace Nteff, Laura Pinkney \\ School of Nursing, Clayton State University, Morrow, GA, USA \\ Email: victoriafoster@clayton.edu
}

How to cite this paper: Foster, V., Collins, E., Dong, H., Nteff, G. and Pinkney, L. (2017) Teaching Clinical Pharmacology to Undergraduate Nursing Students: Barriers and Strategies. Open Journal of Nursing, 7, 918-929.

https://doi.org/10.4236/ojn.2017.78068

Received: May 14, 2017

Accepted: August 15, 2017

Published: August 18, 2017

Copyright (c) 2017 by authors and Scientific Research Publishing Inc. This work is licensed under the Creative Commons Attribution International License (CC BY 4.0).

http://creativecommons.org/licenses/by/4.0/

\begin{abstract}
This study examined perceived learning barriers to and strategies for teaching clinical pharmacology to undergraduate nursing students. The purposes of this study were to discuss barriers and strategies for teaching clinical pharmacology to undergraduate nursing students and compare those findings to student evaluation responses. This study used a comparative, cross-sectional design and examined data from nursing faculty who had taught pharmacology and from student evaluations over the past five years to compare perceived barriers and strategies. Several barriers were identified, including content saturation, course placement, English as a second language, and resources. Effective teaching strategies identified were lectures, teaching by drug class, reviewing pathophysiology, and case studies. Students' evaluations revealed that students found that the course content was substantial and felt that the textbook did not fully demonstrate nursing considerations. Other answers were nonspecific. Using these strategies is critical to effectively deliver pharmacological material and to foster understanding among undergraduate students. Faculty members agree that having pharmacological concepts threaded throughout the curriculum increases students' knowledge of medications and medication management. Additional creative approaches to teaching clinical pharmacology to undergraduate nursing students are needed.
\end{abstract}

\section{Keywords}

Pharmacology, Students, Learning, Strategies, Nursing

\section{Introduction}

Learning pharmacology involves much more than memorization; it requires understanding the mechanisms of action, side effects, and nursing considera- 
tions involved in drug administration. A clinical pharmacology course should therefore help undergraduate nursing students understand the pharmacokinetics and pharmacodynamics of medications and develop the knowledge base necessary to administer medications effectively and safely to patients with various health problems. However, because pharmacology encompasses such a broad spectrum of information, undergraduate nursing students often find the subject matter difficult. This article contains a discussion of issues that sometimes serve as barriers to learning and provides strategies that help students be successful in an undergraduate nursing pharmacology course.

Challenges with nursing pharmacology courses and "information overload" [1] are often expressed by nursing students. The challenges include the amount of material that is often compressed into lectures [1] [2] [3] and the limited amount of time instructors have to present the information [2] [4]. Most pharmacology courses are taught in one 2 - 3 hour lecture per week; which may not allow for comprehensive delivery of content.

One issue in students' learning pharmacology is lack of preparation or insufficient knowledge on the part of the pharmacology instructor [5] [6]. This finding is not limited to nursing pharmacology instructors. In an early study, Markowitz, Pearson, Kay, and Loewenstein [7] noted that knowledge deficits of faculty who taught pharmacists, physicians, and nurses were in part responsible for practitioners' inadequate knowledge. A 25-item questionnaire was used to determine practitioners' knowledge of drugs, actions, dosages, interactions, and administration [7]. The practitioners' average knowledge scores were less than $90 \%$ with pharmacists, physicians, and nurses having knowledge scores of $85 \%$, $81 \%$, and $72 \%$ respectively. Gwee [8] identified the same problem among the medical student population. Recent studies reported insufficient pharmacology knowledge among undergraduate students [9] [10]; however, the increasing numbers of new drugs appearing in the market and greater complexity of pharmacological therapy mandate nursing programs provide strong pharmacology courses.

Clearly, there is a need to assure the structure of nursing courses to assist students with knowledge attainment and retention. Modifying existing teaching approaches may be necessary for knowledge attainment and retention in nursing pharmacology. Meechan, Mason, and Catling [3] developed and tested an integrative approach to pharmacology using 120 nursing students. The approach included providing a pharmacology supplement to nursing students in their first year of nursing school. This supplement provided four 3-hour lectures (12 hours maximum) on the basic concepts of 1) absorption, 2) distribution, 3) metabolism, and 4) half-life. The supplement also included information on common drug classes (e.g., analgesics, antihypertensives, bronchodilators, and antidiabetics) but excluded specialty drug classes. The researchers found that the intervention group demonstrated a higher level of pharmacological knowledge than the control group. 
Ventura and Onsman [11] conducted a cohort study $(n=208)$ to determine the effectiveness of video clips in a nursing pharmacology course. Short video clips relevant to the content area for specific pharmacologic topics were used to reinforce learning. The results revealed that more than $95 \%$ of the students enjoyed the use of the video clips and better retained the information [11].

While these strategies to promote student learning in pharmacology appeared effective, it remains unclear what the main barriers are to learning pharmacology and what the most effective strategies are to overcome these barriers. A review of the literature found a need to reexamine the structure nursing and health science pharmacology courses to assist students with knowledge attainment and retention. Incorporating successful strategies into the curriculum and modifying the approaches to lecture may be the alterations needed for knowledge attainment and retention in nursing pharmacology.

\section{Methods}

A descriptive, comparative, cross-sectional research design was used in this study.

Five nursing faculty at a public university in a metropolitan city in the southeastern United States were asked to identify various barriers and strategies for learning pharmacology. Following a discussion of the identified barriers and strategies, they came to a consensus and identified four barriers and four strategies to teaching and learning pharmacology.

Student evaluations from 5 years were reviewed to determine if they supported the barriers and strategies identified by faculty. Students had concerns about the amount of material they were required to learn and about the book used for the course. They identified songs and case studies as effective in helping them relate the information to the clinical setting. However, other responses were vague and pertained to the course or the instructor. Therefore, the authors created a questionnaire based on faculty responses to use with future classes. The questionnaire contains nine demographic items and 12 Likert-scaled items, with the anchors ranging from 1 (strongly disagree) to 4 (strongly agree). Some of the items were: 1) Content saturation is a barrier to learning pharmacology, 2) Placement of pharmacology course in the curriculum is a barrier to learning pharmacology, 3) Student characteristics such as English as a second language is a barrier to learning pharmacology and 4) Lecture format is an effective strategy for learning pharmacology.

For the purposes of this article, only items asking about the four barriers and four teaching strategies identified by the faculty were used in an analysis of the students' responses. The questionnaire was created online using the Qualtrics research platform. Volunteers were solicited from three nursing classes in summer 2015, fall 2015 and spring 2016. Those students who volunteered to participate in the study were sent a link to the online survey using their class email addresses. The students were also asked a number of questions about their gender, 
age, race, and types of courses they had taken. Not all respondents provided answers to all items. A series of $t$ tests and one-way analyses of variance were used to determine differences between the students on their perceptions of the barriers and teaching strategies. This study was approved by the Clayton State University Institutional Review Board.

\section{Results}

\subsection{Sample}

Responses were obtained from faculty and students. Four of the five female faculty members were full-time instructors who taught clinical pharmacology, while the fifth participant was a part-time faculty member who had previously taken the course. The faculty members were from diverse backgrounds and one spoke English as a second language. Ages ranged from 30 to 55 years old, and the faculty had taught pharmacology for an average of 4 years. They had varied clinical backgrounds ranging from critical care to medical-surgical nursing.

Usable responses were received from 55 students. Almost all of the respondents were seniors, three quarters were female, $64 \%$ were between 21 and 29 , $35 \%$ were White, and $36 \%$ were Black (see Table 1). This was a convenience sample. Thirteen percent of the respondents reported that English was not their first language. More than half of the respondents had taken the pharmacology course two semesters before responding to the questionnaire, while only $29 \%$ of the students had taken it one semester earlier. The majority of the students had taken medical-surgical nursing 3, approximately one third had taken maternal-child nursing or pediatric nursing, while only $11 \%$ had taken medical-surgical nursing 2 or psychiatric nursing. Twenty-five percent of the students indicated that they worked as a certified nursing assistant (CNA) or nurse tech.

\subsection{Barriers}

The four barriers identified by faculty included content saturation, course placement in the curriculum, English as a second language for some learners, and resources. These barriers must be addressed so that nursing graduates are prepared to enter into a complex health care environment with the skills necessary to administer medications appropriately.

Content saturation. From the pre-administration assessment to the seven rights of medication administration, students need to learn a plethora of information to manage medications efficiently. Side effects, proper dosages, nursing considerations, and evaluation of therapeutic effects must be incorporated into a pharmacology course. Nursing students often complain that the extensive amount of information makes the course difficult. Giddens and Brady [12] noted that when the focus is on content, the volume covered is high, but retention of information is low because of a failure to achieve deep understanding. Students attempt to memorize content that they cannot understand but are required to know to pass exams in the course. 
Table 1. Description of sample.

\begin{tabular}{|c|c|c|}
\hline Characteristic & $\mathrm{n}$ & $\%$ \\
\hline \multicolumn{3}{|l|}{ Gender } \\
\hline Male & 13 & 23.6 \\
\hline Female & 42 & 76.4 \\
\hline \multicolumn{3}{|l|}{ Age } \\
\hline $21-22$ & 15 & 27.3 \\
\hline $23-29$ & 20 & 36.34 \\
\hline $30-39$ & 12 & 21.8 \\
\hline $40-49$ & 7 & 12.7 \\
\hline Over 50 & 1 & 1.8 \\
\hline \multicolumn{3}{|l|}{ Race } \\
\hline White & 19 & 34.5 \\
\hline Black & 20 & 36.4 \\
\hline Hispanic & 2 & 3.6 \\
\hline Asian & 9 & 16.4 \\
\hline Other & 5 & 9.1 \\
\hline \multicolumn{3}{|l|}{ Class } \\
\hline Junior & 1 & 1.8 \\
\hline Senior & 54 & 98.2 \\
\hline \multicolumn{3}{|l|}{ Primary language } \\
\hline English & 47 & 87.0 \\
\hline Other & 7 & 13.0 \\
\hline \multicolumn{3}{|l|}{ When took pharmacology } \\
\hline One semester ago & 16 & 29.1 \\
\hline Two semesters ago & 35 & 58.2 \\
\hline Three semesters ago & 7 & 12.7 \\
\hline \multicolumn{3}{|l|}{ Courses taken } \\
\hline Maternal-Child Nursing & 18 & 34.0 \\
\hline Medical-Surgical Nursing 2 & 6 & 11.3 \\
\hline Medical-Surgical Nursing 3 & 29 & 54.7 \\
\hline Pediatric Nursing & 17 & 32.1 \\
\hline Psychiatric Nursing & 6 & 11.3 \\
\hline Work as a CNA or Nurse Tech & 14 & 25.5 \\
\hline
\end{tabular}

Course placement in the curriculum. Pharmacology courses are placed in the curriculum at different levels of the nursing program. Some universities require students to take pharmacology in the sophomore year prior to being accepted into the nursing program and prior to taking the fundamentals in nursing course. Others place the course in the junior year after students have been accepted into the nursing program and have begun administering medications in the clinical setting. Each placement can pose problems. Students in the earlier 
placement discuss medications without any clinical practice in medication administration that can reinforce learning and critical thinking. In the later placement, students administer medications in clinical settings without having had a formal pharmacology course where they learn the pharmacokinetics and pharmacodynamics of medications.

Placement of our pharmacology course during the second semester of the junior year can be a burden to students because a second medical surgical nursing course and a psychosocial nursing course is required to be taken simultaneously with pharmacology. While some students have found this placement of courses helpful, the majority have expressed frustration and feelings of being overwhelmed. They have stated that much of their time is spent memorizing for exams, not thoroughly learning and grasping the concepts in the courses.

English as a second language. Some student characteristics increase difficulty in teaching pharmacology. English as a second language (ESL) can sometimes pose a problem for students; however, retention and graduation of ESL nursing students are essential to diversify the nursing workforce [13]. ESL students may be cognitively and psychologically overwhelmed with the demands of immersion. In addition, ESL students have different levels of English language proficiency. These students frequently dissect exam questions and many times ask the meaning of words. When a separate medical terminology course is not offered, some ESL students learn nursing/medical terms only as they transition from one course to another.

Resources. The appropriate resources are necessary to enhance learning of pharmacology. There is an abundance of pharmacology books to choose from for students. Some are undemanding, while others are more chemical or pharmacology focused. The initial book used by our students was extremely chemical focused and could probably be used for an advanced pharmacology course. As a result, the book was changed to a more nursing focused book. Other resources that can be helpful include clinical drug books, electronic drug question databases, $\mathrm{ATI}^{\oplus}$ or Kaplan practice tests, and drug APPs.

\subsection{Strategies}

In additional to teaching the pharmacology course, our faculty members thread pharmacology concepts throughout the curriculum. The faculty members use a number of strategies to help undergraduate nursing students learn the principles of pharmacology. These include lecture, teaching by drug class, review of pathophysiology, and case studies.

Lectures. Lectures provide the foundation of what should be learned by the student. The lecture approach provides a way to communicate a large amount of information to a captive audience, maximizing faculty control and being non-threatening to students. To assist students who may have missed a lecture, recordings via Camtasia Relay ${ }^{\circledast}$ can be made and posted to the class website. Students are also allowed to tape lectures during presentations. If patient infor- 
mation is discussed, students are instructed to turn off recorders, and identifying information is never discussed.

Teaching by drug class. A large amount of information is presented in pharmacology, and students try to learn each individual drug along with side effects, dosages, and nursing considerations. However, many medications in the same class have the same prefix or suffix; for example, the generic names of beta-blockers end in 101 . If students learn medications by drug class, this increases their knowledge of many drugs that look like the prototype drug. The use of games and songs when teaching medications by class can enhance retention of information about a given drug class [12]. Students have commented that learning drugs by classes has helped with learning and identifying medications on exams.

Reviewing pathophysiology. Drugs affect different body processes; therefore, reviewing pathophysiology is essential for understanding the effects of medications. Students are seldom tested on the pathophysiology of different diseases or conditions; however, they do receive an explanation of how the drug will affect the body and alter the disease process, and they are expected to know the actions of medications. Reviewing pathophysiology when teaching pharmacology allows students to grasp the interrelationships between the diagnosis and the medications used to treat the conditions. Tse and Lo [14] found that students felt learning pathophysiology and pharmacology together allowed them to understand rather than memorize the content. The students also felt that this improved their problem solving and critical thinking [14].

Case studies. Case studies promote the skills of critical thinking, problem solving, and decision making [15]. They present realistic situations that students will probably encounter in the clinical setting. In addition, case studies can be used to address issues that students may have missed in the clinical setting. Case studies are usually faculty developed, but some are already created by $\mathrm{ATI}^{\circledast}$ or other companies. In some cases, medical-surgical case studies can be modified to add pharmacological principles and allow for application of knowledge about drug class, side effects, nursing considerations, and other aspects of medication administration. Case studies can be used in the classroom before and/or after the lecture to help students synthesize the information they have read or heard. Some faculty are even flipping the classroom and using case studies in lieu of lectures. This is not recommended for new students, but case studies can definitely enhance lectures.

\subsection{Student Responses}

Table 2 contains the means and standard deviations of the students' responses to the eight questionnaire items of interest. Students did not consider resources to be a barrier $(M=2.20)$ as much as they did feel that content saturation was a barrier $(M=3.19)$. Students were more likely to agree that teaching by drug class $(M=3.60)$ was a more effective teaching strategies than were case studies $(M=$ 2.67). 
Table 2. Total student responses.

\begin{tabular}{ccc}
\hline Item & M & SD \\
\hline Barrier & 3.19 & \\
Content saturation & 2.93 & 0.78 \\
Placement in curriculum & 2.63 & 0.77 \\
Student characteristics & 2.20 & 0.92 \\
Resources & & 0.83 \\
Strategies & 3.15 & \\
Lecture format & 3.19 & 0.74 \\
Reviewing pathophysiology & 2.67 & 0.62 \\
Case studies & 3.60 & 0.80 \\
Teach by drug class & & 0.53 \\
\hline
\end{tabular}

a. Means range from 1 (strongly disagree) to 4 (strongly agree).

\subsection{Barriers to Learning Pharmacology}

The data were analyzed according to how the students responded to questions that sought information about their primary language, if they had taken medical-surgical nursing 3 , if they were a CNA or tech nurse, how many courses they had taken, and when they took the pharmacology course. See Table 3 for barriers to learning the means across each group.

The statistically significant findings are highlighted with an asterisk. There were several statistically significant findings. First, although rated disagree, students who worked as a CNA or nurse tech $(M=2.71)$ were statistically more likely than students who did not work as a CNA or nurse tech $(M=2.02)$ to indicate that resources were a barrier to learning pharmacology. Secondly, students whose primary language was not English $(M=3.50)$ were statistically more in agreement that student characteristics were a barrier to learning pharmacology than students whose primary language was English $(M=2.55)$. Students who took pharmacology three semesters ago $(M=3.67)$ were more likely to agree that placement in the curriculum was a barrier to learning pharmacology than students who took the course one $(M=2.81)$ or two $(M=2.84)$ semesters ago. In addition, students who took pharmacology three semesters ago $(M=$ 2.86) were statistically more likely to agree that resources were a barrier to learning pharmacology than students who took the course one $(M=1.94)$ or two $(M=2.19)$ semesters ago.

\subsection{Effective Teaching Strategies}

Table 4 contains the teaching strategies for learning pharmacology and the students' means across each group. The statistically significant findings are highlighted with an asterisk. There were 2 significant findings. Students who worked as a CNA or nurse tech $(M=3.54)$ were statistically more likely than students who did not work as a CNA or nurse tech $(M=3.07)$ to indicate that reviewing pathophysiology was an effective strategy for learning pharmacology. 
Table 3. Significant mean differences found among students-barriers.

\begin{tabular}{|c|c|c|c|c|}
\hline \multirow[b]{2}{*}{ Comparison } & \multicolumn{4}{|c|}{ Barriers } \\
\hline & $\begin{array}{c}\text { Content } \\
\text { saturation }\end{array}$ & $\begin{array}{l}\text { Placement in } \\
\text { curriculum }\end{array}$ & $\begin{array}{c}\text { Student } \\
\text { characteristics }\end{array}$ & Resources \\
\hline \multicolumn{5}{|l|}{ CNA or Nurse Tech } \\
\hline Yes $(n=14)$ & 3.50 & 3.08 & 2.64 & $2.71^{*}$ \\
\hline No $(n=41)$ & 3.08 & 2.88 & 2.63 & 2.02 \\
\hline \multicolumn{5}{|l|}{ English as a second language } \\
\hline No $(n=47)$ & 3.17 & 2.93 & 2.55 & 2.19 \\
\hline Yes $(n=7)$ & 3.43 & 3.00 & $3.50^{*}$ & 2.43 \\
\hline \multicolumn{5}{|l|}{ Taken Medical-Surgical Nursing 3} \\
\hline Yes $(n=28)$ & 3.32 & 2.93 & 2.57 & 2.31 \\
\hline No $(n=24)$ & 3.00 & 2.92 & 2.75 & 2.00 \\
\hline \multicolumn{5}{|l|}{ Number of courses taken } \\
\hline 1 course $(n=36)$ & 3.29 & 2.89 & 2.60 & 2.25 \\
\hline 2 or more courses $(n=17)$ & 2.94 & 3.00 & 2.76 & 2.00 \\
\hline \multicolumn{5}{|l|}{ When took pharmacology } \\
\hline 1 semester ago $(n=16)$ & 3.06 & 2.81 & 2.69 & 1.94 \\
\hline 2 semesters ago $(n=32)$ & 3.16 & 2.84 & 2.61 & 2.19 \\
\hline 3 semesters ago $(n=7)$ & 3.57 & $3.67^{\star}$ & 2.57 & $2.86^{*}$ \\
\hline
\end{tabular}

a. Means range from 1 (strongly disagree) to 4 (strongly agree). b. ${ }^{*}$ Statistically significant differences between (or among) the means $(p<0.05)$.

Table 4. Significant mean differences found among students-strategies.

\begin{tabular}{|c|c|c|c|c|}
\hline \multirow[b]{2}{*}{ Comparison } & \multicolumn{4}{|c|}{ Strategies } \\
\hline & $\begin{array}{l}\text { Lecture } \\
\text { format }\end{array}$ & $\begin{array}{c}\text { Reviewing } \\
\text { pathophysiology }\end{array}$ & Case studies & $\begin{array}{c}\text { Teaching by } \\
\text { drug class }\end{array}$ \\
\hline \multicolumn{5}{|l|}{ CNA or Nurse Tech } \\
\hline Yes $(n=14)$ & 3.29 & $3.54^{*}$ & 3.00 & 3.64 \\
\hline No $(n=41)$ & 3.10 & 3.07 & 2.56 & 3.59 \\
\hline \multicolumn{5}{|l|}{ English as a second language } \\
\hline No $(n=47)$ & 3.04 & 3.22 & 2.66 & 3.60 \\
\hline Yes $(n=7)$ & $3.71^{*}$ & 3.00 & 2.71 & 3.57 \\
\hline \multicolumn{5}{|l|}{ Taken Medical-Surgical Nursing 3} \\
\hline Yes $(n=28)$ & 3.17 & 3.17 & 2.75 & 3.58 \\
\hline No $(n=24)$ & 3.14 & 3.14 & 2.52 & 3.59 \\
\hline \multicolumn{5}{|l|}{ Number of courses taken } \\
\hline 1 course $(n=36)$ & 3.26 & 3.17 & 2.53 & 3.61 \\
\hline 2 or more courses $(n=17)$ & 2.94 & 3.12 & 2.82 & 3.53 \\
\hline \multicolumn{5}{|l|}{ When took pharmacology } \\
\hline 1 semester ago $(n=16)$ & 3.40 & 3.13 & 2.63 & 3.69 \\
\hline 2 semesters ago $(n=32)$ & 3.03 & 3.19 & 2.69 & 3.53 \\
\hline 3 semesters ago $(n=7)$ & 3.14 & 3.29 & 2.71 & 3.71 \\
\hline
\end{tabular}

a. Means range from 1 (strongly disagree) to 4 (strongly agree). b. *Statistically significant differences between (or among) the means $(p<0.05)$. 
The second finding was students whose primary language was not English $(M=$ 3.50) were statistically more likely to indicate that the lecture format was an effective strategy for teaching pharmacology than students whose primary language was English $(M=3.04)$.

\section{Discussion}

Common goals for faculty teaching pharmacology include student success in the course, application of pharmacology knowledge in clinical practice, and eventually, success on the National Council Licensure Examination. Simple teaching strategies-were used in teaching this course to enhance retention of pharmacology content and overall student success. It is evident that memorization of pharmacology content as a learning strategy is overwhelming to students, and it might not lead to positive outcomes for the students. Although we have a formal pharmacology course, the faculty teaching this course also taught clinical. They noted that a review of didactic content from the classroom during student administration of pharmacologic agents in the clinical setting, enhanced retention and application of pharmacology knowledge. Therefore, pharmacology content should be taught in the clinical setting, threaded and reviewed in all clinical courses where students handle and administer drugs to patients.

Using a combination of lectures and effective teaching strategies, such as reviewing the pathophysiology of the diagnosis, creates a link for students between the mechanism of action of a drug and the disease process, and enhances their ability to evaluate the effectiveness of the medication. Using drug classifications as a teaching strategy enables easy recognition of a drug class and application of the pharmacokinetics and pharmacodynamics of the prototype drug to any given drug. Case studies are widely used to assist students with applying pharmacology knowledge to real patient care situations, although students did not particularly see this as an effective strategy. Finally, based on our faculty experiences and student responses, we recommend teaching pharmacology by drug class. This allows the student to identify a prototype and relate other drugs in the same class to easily learn side effects and nursing considerations. Further, since ESL students felt that lecturing was an effective strategy, lectures should always be included regardless of other strategies used.

\section{Conclusions}

Findings from this cross sectional survey of students are limited due to a small sample size and replication of the study with a larger sample is recommended for generalization of findings. The participants were obtained from a convenience sample which can lead to sample bias or sampling error. Another limitation was the use of one university as the study site. Using a multi-site approach may have allowed the authors to obtain perspectives from different types of student bodies which could lead to a more in depth evaluation of barriers and effective strategies for teaching pharmacology. In addition, most of the individuals in the sam- 
ple were senior and English speaking students which didn't allow for comparisons among groups. Finally, the course was taught by different professors. Although the pharmacology content was the same for each course, differences in personal style, autonomy, and teaching skills could lead to performance bias.

This study examined barriers to and strategies for teaching pharmacology to undergraduate nursing students. Findings from this study may contribute data to facilitate nursing faculty with the development of successful pharmacology courses. The results from this study support previous studies demonstrating the importance of a well-developed pharmacology course to prepare nursing students and new nurses to effectively administer medications. Although further studies are needed to support and elucidate these findings, this is one of the first studies to compare barriers and strategies reported by both faculty and students. A greater awareness of barriers and strategies of teaching pharmacology can help guide nursing faculty in preparing courses that better prepare students in addressing the complex medication needs of the populations they serve.

\section{Acknowledgements}

We would like to thank our students and their contribution toward increasing effective teaching strategies.

\section{References}

[1] Honey, M. and Lim, A. (2008) Application of Pharmacology Knowledge in Medication Management by Final Year Undergraduate Nursing Students. Contemporary Nurse, 30, 12-19. https://doi.org/10.5172/conu.673.30.1.12

[2] Manias, E. (2009) Pharmacology Content in Undergraduate Nursing Programs: Is There Enough to Support Nurses in Providing Safe and Effective Care? International Journal of Nursing Studies, 46, 1-3.

[3] Meechan, R., Mason, V. and Catling, J. (2011) The Impact of an Integrated Pharmacology and Medicines Management Curriculum for Undergraduate Adult Nursing Students on the Acquisition of Applied Drug/Pharmacology Knowledge. Nursing Education Today, 31, 383-389.

[4] Page, K. and McKinney, A. (2007) Addressing Medication Errors: The Role of Under Graduate Nurse Education. Nurse Education Today, 27, 219-224.

[5] Bullock, S. and Manias, E. (2002) The Educational Preparation of Undergraduate Nursing Students in Pharmacology: A Survey of Lecturer's Perceptions and Experiences. Advanced Nursing, 40, 7-16. https://doi.org/10.1046/j.1365-2648.2002.02335.x

[6] King, R. (2004) Nurses Perceptions of Their Pharmacological Educational Needs. Advanced Nursing, 45, 392-400. https://doi.org/10.1046/j.1365-2648.2003.02922.x

[7] Markowitz, J., Pearson, G., Kay, B. and Loewenstein, R. (1981) Nurses, Physicians and Pharmacists: Their Knowledge of Hazards of Medications. Nursing Research, 30, 366-370. https://doi.org/10.1097/00006199-198111000-00019

[8] Gwee, M.C. (2009) Problem-Based Learning: A Strategic Learning System Design for the Education of Healthcare Professionals in the 21st Century. Kaosiung Journal of Medicine, 25, 231-239. 
[9] Dilles, T., Stichele, V., Bortel, B. and Elseviers, M.M. (2011) Nursing Students' Pharmacological Knowledge and Calculation Skills: Ready for Practice? Nurse Education Today, 31, 499-505.

[10] Barkhouse-MacKeen, C.D. and Murphy, A.C. (2013) Renal Unit Practitioner's Knowledge, Attitudes and Practice Regarding the Safety of Unfractionated Heparin for Chronic Hemodialysis. Curations, 38, 1-12.

[11] Ventura, S. and Onsman, A. (2009) The Use of Popular Movies during Lectures to Aid the Teaching and Learning of Undergraduate Pharmacology. Medical Teacher, 31, 662-664. https://doi.org/10.1080/01421590802641489

[12] Giddens, J.F. and Brady, D.P. (2007) Rescuing Nursing Education from Content Saturation: The Case for a Concept-Based Curriculum. Nursing Education, 46, 6569.

[13] Greenberg, N.E. (2013) A Project to Increase Faculty's Cultural Competence in Mentoring English as a Second Language Nursing Students. Teaching and Learning in Nursing, 8, 128-135.

[14] Tse, M.M.Y. and Lo, L.W.L. (2008) A Web-Based E-Learning Course: Integration of Pathophysiology into Pharmacology. Telemedicine and E-Health, 14, 919-924. https://doi.org/10.1089/tmj.2008.0006

[15] Desanto-Madeva, S. (2007) Using Case Studies Based on a Nursing Conceptual Model to Teach Medical-Surgical Nursing. Nursing Science Quarterly, 20, 324-329. https://doi.org/10.1177/0894318407307159

Submit or recommend next manuscript to SCIRP and we will provide best service for you:

Accepting pre-submission inquiries through Email, Facebook, LinkedIn, Twitter, etc. A wide selection of journals (inclusive of 9 subjects, more than 200 journals) Providing 24-hour high-quality service User-friendly online submission system Fair and swift peer-review system Efficient typesetting and proofreading procedure Display of the result of downloads and visits, as well as the number of cited articles Maximum dissemination of your research work

Submit your manuscript at: http://papersubmission.scirp.org/

Or contact ojn@scirp.org 